\title{
Novel Current Error Space Phasor Based Hysteresis Controller Using Parabolic Bands for Control of Switching Frequency Variations
}

\author{
P. N. Tekwani, Student Member, IEEE, R. S. Kanchan, Student Member, IEEE, and \\ K. Gopakumar, Senior Member, IEEE
}

\begin{abstract}
A current error space phasor based simple hysteresis controller is proposed in this paper to control the switching frequency variation in two-level pulsewidth-modulation (PWM) inverter-fed induction motor (IM) drives. A parabolic boundary for the current error space phasor is suggested for the first time to obtain the switching frequency spectrum for output voltage with hysteresis controller similar to the constant switching frequency voltage-controlled space vector PWM-based IM drive. A novel concept of online variation of this parabolic boundary, which depends on the operating speed of motor, is presented. A generalized technique that determines the set of unique parabolic boundaries for a two-level inverter feeding any given induction motor is described. The sector change logic is self-adaptive and is capable of taking the drive up to the six-step mode if needed. Steady-state and transient performance of proposed controller is experimentally verified on a 3.7-kW IM drive in the entire speed range. Close resemblance of the simulation and experimental results is shown.
\end{abstract}

Index Terms-Current error space phasor, hysteresis controller, parabolic boundary, switching frequency variation control.

\section{INTRODUCTION}

A MONG the different types of current-controlled pulsewidth modulation (PWM) techniques, hysteresis controllers offer inherent simplicity in implementation and excellent dynamic performance [1], [2]. However, the conventional type of hysteresis controller suffers from limit cycle oscillations, overshoot in current error, generation of subharmonic components in current, and random switching of inverter voltage vectors [1]-[3]. To eliminate these basic drawbacks, different variants of current error space phasor based hysteresis controllers with fixed tolerance bands are reported in the literature [2], [4]-[12]. However, hysteresis controllers with fixed bands suffer from wide variations in switching frequency in a fundamental cycle [1]-[3], [7], [8], [12]-[14], which results in increased switching losses in the inverter.

A phase-locked-loop (PLL) control-based hysteresis controller is proposed in [13] for constant switching frequency operation of the inverter. However, the PLL proposed in [13] might lose synchronization in case of large transients. The adaptive hysteresis band current control technique presented

Manuscript received April 27, 2006; revised February 2, 2007.

P. N. Tekwani was with the Centre for Electronics Design and Technology, Indian Institute of Science, Bangalore 560 012, India. He is now with Nirma University of Science and Technology, Ahmedabad 382 481, India.

R. S. Kanchan and K. Gopakumar are with the Centre for Electronics Design and Technology, Indian Institute of Science, Bangalore 560 012, India (e-mail: kgopa@cedt.iisc.ernet.in).

Digital Object Identifier 10.1109/TIE.2007.899849

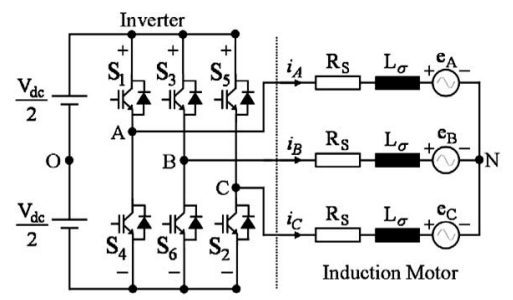

(a)

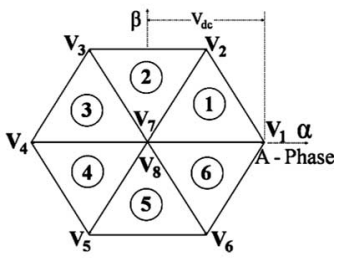

(b)
Fig. 1. Three-phase two-level VSI-fed IM drive. (a) Power schematic. (b) Voltage space phasor structure.

in [14] programs the hysteresis band as a function of load and supply parameters to optimize the PWM performance. An improved constant-frequency hysteresis controller, which is proposed in [16], uses a complex analog feedforward for the prediction of the band in addition to PLL control. However, the band control schemes presented in [13]-[16] are either complex to implement, require extensive knowledge of the system parameters, suffer from stability problems, or have limitations in transient performance. Also, more importantly, although efforts are made in [13]-[16] to control the switching frequency in a fundamental cycle, the variation of switching frequency over the operating speed range of the machine is not examined. A digital hysteresis modulation technique ensuring dynamic performance similar to an analog hysteresis controller is proposed in [19].

In this paper, a hysteresis controller with a novel concept of online variation of parabolic boundary for the current error space phasor is proposed for controlling switching frequency variation in two-level inverter-fed induction motor (IM) drives. The switching frequency spectrum of the output voltage with the proposed hysteresis controller is obtained similar to that of a constant switching frequency voltage controlled space vector PWM (VC-SVPWM) based IM drive. Steady-state and transient performance of the proposed controller is experimentally verified on a $3.7-\mathrm{kW}$ IM drive for the entire operating range up to six-step mode of operation. The proposed scheme is general in nature and is applicable for a two-level voltagesource inverter (VSI) feeding any given induction motor.

\section{Current Error Space Phasor Based HYSTERESIS CONTROLLER}

Fig. 1(a) shows the power schematic of a two-level VSI-fed IM drive. Its voltage space phasor structure is shown 


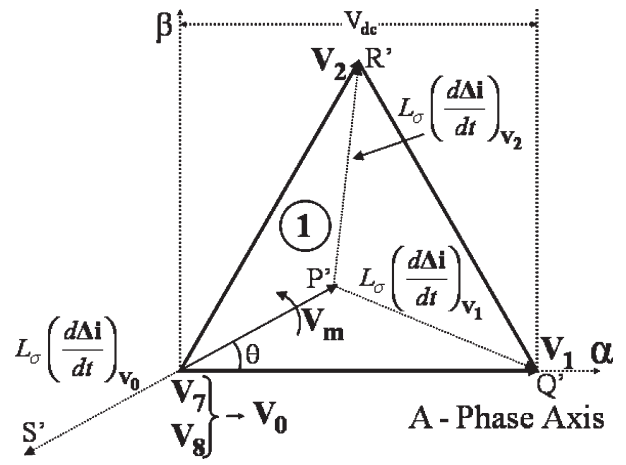

Fig. 2. Directions of current error space phasor for the inverter vector switchings when $\mathbf{V}_{\mathbf{m}}$ is in Sector-1.

in Fig. 1(b) [17]. At any instant of time, if $\Delta i_{A}, \Delta i_{B}$, and $\Delta i_{C}$ are the current errors along $\mathrm{A}, \mathrm{B}$, and $\mathrm{C}$ phases of the motor, respectively, then the current error space phasor $(\Delta \mathbf{i})$ can be written as [10], [12]

$$
\begin{aligned}
& \Delta \mathbf{i}=\Delta i_{A}+\Delta i_{B} e^{j(2 \pi / 3)}+\Delta i_{C} e^{j(4 \pi / 3)} \\
& \Delta \mathbf{i}=\mathbf{i}-\mathbf{i}^{*} .
\end{aligned}
$$

In (1), $\Delta \mathbf{i}$ is derived as a vectorial difference of the machine current space phasor (i) and the reference current space phasor $\left(\mathbf{i}^{*}\right)$ [10], [12]. If the inverter output voltage vector is defined as $\mathbf{V}_{\mathbf{k}}$ ( $\mathbf{k}$ can be any value between 1 and 8$)$, then the voltage and current equation for the IM drive in Fig. 1(a) is given by

$$
\mathbf{V}_{\mathbf{k}}=R_{s} \mathbf{i}+L_{\sigma} \frac{d \mathbf{i}}{d t}+\mathbf{V}_{\mathbf{b}}, \quad \text { where } \mathbf{i}=\Delta \mathbf{i}+\mathbf{i}^{*}
$$

where $R_{s}$ is the stator resistance, $L_{\sigma}$ is the leakage inductance, and $\mathbf{V}_{\mathbf{b}}$ is the back electromotive force (EMF) vector of the machine. In (2), $R_{s} \Delta \mathbf{i}$ can be neglected, and (2) can be further simplified as [4], [10], [12]

$$
\frac{d \Delta \mathbf{i}}{d t}=\frac{\mathbf{V}_{\mathbf{k}}-\mathbf{V}_{\mathbf{m}}}{L_{\sigma}}, \quad \text { where } \mathbf{V}_{\mathbf{m}}=R_{s} \mathbf{i}^{*}+L_{\sigma} \frac{d \mathbf{i}^{*}}{d t}+\mathbf{V}_{\mathbf{b}}
$$

where $\mathbf{V}_{\mathbf{m}}$ is the machine voltage vector. Fig. 2 shows three different directions of $\Delta \mathbf{i}\left(P^{\prime} Q^{\prime}, P^{\prime} R^{\prime}\right.$, and $\left.P^{\prime} S^{\prime}\right)$ when the inverter voltage vectors $\mathbf{V}_{\mathbf{1}}, \mathbf{V}_{\mathbf{2}}$, and $\mathbf{V}_{\mathbf{0}}\left(\mathbf{V}_{\mathbf{7}}\right.$ or $\left.\mathbf{V}_{\mathbf{8}}\right)$ are switched for position of $\mathbf{V}_{\mathbf{m}}$ in Sector-1 [10], [12]. A detailed analysis of the directions of $\Delta \mathbf{i}$ for the switching of different voltage vectors in any of the sectors for any given position of $\mathbf{V}_{\mathbf{m}}$ is provided in [10] and [12].

It can be found from (3) that the inverter switching frequency is influenced by leakage inductance $L_{\sigma}$, machine voltage vector $\mathbf{V}_{\mathbf{m}}$, inverter voltage vector $\mathbf{V}_{\mathbf{k}}$ (dc-link voltage $V_{\mathrm{dc}}$ of inverter), and current error space phasor ripple $(\Delta(\Delta \mathbf{i}))$. Over a fundamental period, the position of $\mathbf{V}_{\mathbf{m}}$ varies, and $\mathbf{V}_{\mathbf{k}}$ also changes [1]. Therefore, for the given operating speed, if shape of the fixed boundary of $\Delta \mathbf{i}$ is not properly selected, then the switching frequency of inverter will vary over a fundamental cycle. Further to this, if the same boundary of $\Delta \mathrm{i}$ is maintained for different operating speeds of the machine, then also the inverter switching frequency will vary. This situation demands for a proper mathematical derivation of boundary for $\Delta \mathbf{i}$ over the entire linear operating range of the drive.

\section{Investigation of Current Error Space Phasor VARIATION IN VC-SVPWM-BASED IM DRIVE}

In VC-SVPWM-based inverter-fed IM drives, the PWM switching interval $\left(T_{S}\right)$ is kept constant, and hence, the switching frequency of the inverter remains constant. For the position of reference voltage space vector $\left(\mathbf{V}_{\mathbf{m}}^{*}\right)$ in any sector, the switching times $T_{1}$ and $T_{2}$ for active voltage vectors and $T_{0}$ for zero voltage vectors are derived as

$$
\begin{aligned}
& T_{1}=\frac{\mathbf{V}_{\mathbf{m}}^{*}}{V_{\mathrm{dc}}} T_{S} \frac{\sin \left(60^{\circ}-\theta\right)}{\sin 60^{\circ}} \\
& T_{2}=\frac{\mathbf{V}_{\mathbf{m}}^{*}}{V_{\mathrm{dc}}} T_{S} \frac{\sin \theta}{\sin 60^{\circ}} \\
& T_{0}=T_{S}-\left(T_{1}+T_{2}\right)
\end{aligned}
$$

where $\theta$ is the angle of $\mathbf{V}_{\mathbf{m}}^{*}$ in degrees in that sector [17]. Hence, each voltage vector remains "ON" for a specified fixed period irrespective of the amplitude and direction of the current error space phasor generated by the SVPWM inverter while switching any particular voltage vector.

Although, generally, there does not exist a concept of monitoring the current error space phasor in SVPWM inverters, efforts are made in this paper to study the behavior of current error space phasor with respect to the varying speed of the IM drive. The outcome of this study provides basis for the proposed work for deciding the variation in the boundary of $\Delta \mathbf{i}$ for a current-controlled VSI-fed IM drive with switching frequency variation control. Now, for SVPWM-based inverterfed IM drives, (3) can be rewritten as

$$
\frac{d \boldsymbol{\Delta} \mathbf{i}}{d t}=\frac{\mathbf{V}_{\mathbf{k}}-\mathbf{V}_{\mathbf{m}}^{*}}{L_{\sigma}} \text { hence } \frac{d \boldsymbol{\Delta} \mathbf{i}_{\left(\mathbf{V}_{\mathbf{k}}\right)}}{d t}=\frac{\Delta \mathbf{V}_{\left(\mathbf{V}_{\mathbf{k}}\right)}}{L_{\sigma}}
$$

where $\Delta \mathbf{V}_{\left(\mathbf{V}_{\mathbf{k}}\right)}=\mathbf{V}_{\mathbf{k}}-\mathbf{V}_{\mathbf{m}}^{*}$. In a given $T_{S}$, considering $\Delta \mathbf{V}_{\left(\mathbf{V}_{\mathbf{k}}\right)}$ and $L_{\sigma}$ as constants, integrating both sides of (5) gives

$$
\begin{aligned}
& \int\left(\frac{d \boldsymbol{\Delta} \mathbf{i}_{\left(\mathbf{V}_{\mathbf{k}}\right)}}{d t}\right) d t=\int\left(\frac{\Delta \mathbf{V}_{\left(\mathbf{V}_{\mathbf{k}}\right)}}{L_{\sigma}}\right) d t \\
& \text { hence } \Delta \mathbf{i}_{\left(\mathbf{V}_{\mathbf{k}}\right)}=\frac{\Delta \mathbf{V}_{\left(\mathbf{V}_{\mathbf{k}}\right)}}{L_{\sigma}} T
\end{aligned}
$$

where $T$ can be either $T_{0}, T_{1}$, or $T_{2}$ depending upon $\mathbf{V}_{\mathbf{k}}$. Now, for any position of $\mathbf{V}_{\mathbf{m}}^{*}$ in any of the given sector in Fig. 1(b), the amplitude of $\Delta \mathbf{i}$ can be theoretically found out using (4) and (6) during switching of different voltage vectors.

Based on Fig. 2, the movement of $\Delta \mathbf{i}$ (on the $\alpha-\beta$ plane when $\mathbf{V}_{\mathbf{m}}^{*}$ is at the middle of Sector-1, $\theta=30^{\circ}$ ) for a few switching intervals is shown in Fig. 3(a) for $10-\mathrm{Hz}$ operation of the SVPWM-based IM drive with $T_{S}=800 \mu$ s. In Fig. 3(a) 


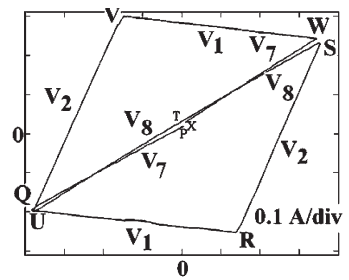

(a)
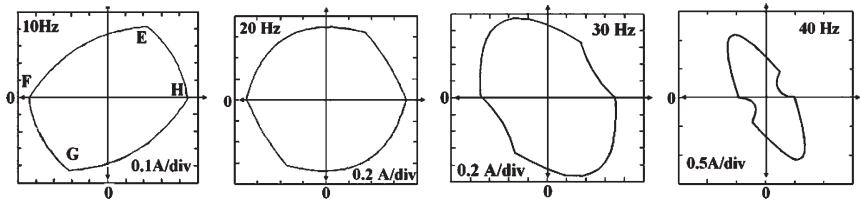

(b)

Fig. 3. (a) Movement of current error space phasor on the $\alpha-\beta$ plane when $\mathbf{V}_{\mathbf{m}}^{*}$ is at middle of Sector- $1\left(\theta=30^{\circ}\right)$. (b) Approximate theoretical boundary of $\Delta \mathbf{i}$ for SVPWM-based two-level VSI-fed IM drive for position of $\mathbf{V}_{\mathbf{m}}^{*}$ in Sector-1 for different operating speeds in hertz.

[using (4) and (6)], $P Q$ is the direction of $\Delta \mathbf{i}$ when $\mathbf{V}_{\mathbf{7}}$ is switched for $T_{0} / 2$ duration in a $T_{S}$ period of SVPWM control. Similarly, when $\mathbf{V}_{\mathbf{1}}$ is switched for $T_{1}$ duration, $\boldsymbol{\Delta} \mathbf{i}$ moves along $Q R$, and so on. To get an idea about the shape of the boundary of $\Delta \mathrm{i}$, the movement (trajectory) of $\Delta \mathrm{i}$ is studied for switching off different voltage vectors for different positions of $\mathbf{V}_{\mathbf{m}}^{*}$ (for various speeds of machine) throughout Sector-1. Then, the extreme points (envelope) of these trajectories are joined (interpolated) with a curve. As an example, a theoretical boundary of $\Delta \mathbf{i}$ for positions of $\mathbf{V}_{\mathbf{m}}^{*}$ in Sector-1 is shown in Fig. 3(b) for different operating speeds.

The drive system is simulated for constant switching frequency VC-SVPWM operation $\left(T_{S}=800 \mu \mathrm{s}, V_{\mathrm{dc}}=\right.$ $350 \mathrm{VDC}$, and $L_{\sigma}=0.0465 \mathrm{H}$ ), and the trajectory of $\Delta \mathbf{i}$ in a sector for different speeds of operation is shown in Fig. 4(a). The trajectory of $\Delta \mathbf{i}$ for a fundamental cycle of operation is shown in Fig. 4(b) for various operating speeds. The motor phase voltage and phase current waveforms and the normalized harmonic spectrum (fast Fourier transform, FFT) of phase voltage for 10- and 41-Hz operation are shown in Fig. 4(c) and (d), respectively. From Fig. 4(a) and (b), the envelope (boundary limit) of $\Delta \mathbf{i}$ can be deduced for the proposed hysteresis controller. It can be seen from Figs. 3(b) and 4(a) and (b) that for a given operating speed, the shape of the boundary for $\Delta \mathbf{i}$ is the same for all sectors, but the orientation will change. Also, as shown in Fig. 4(a), the orientation of the boundary for $\Delta \mathrm{i}$ is the same for opposite sectors of the voltage space phasor structure, such as Sector-2 and Sector-5 [Fig. 1(b)]. It can be observed that the theoretically computed boundary of $\Delta \mathbf{i}[\mathrm{Fig}$. 3(b)] matches in shape and size with the boundary obtained in simulation studies [Fig. 4(a)].

\section{ESTABLISHING VARIABLE BOUNDARY FOR CURRENT ERROR SPACE PHASOR IN PROPOSED HYSTERESIS CONTROLLER}

A careful look at Figs. 3(b) and 4(a) shows that the boundary of $\Delta \mathbf{i}$ in any sector can be approximately considered to be
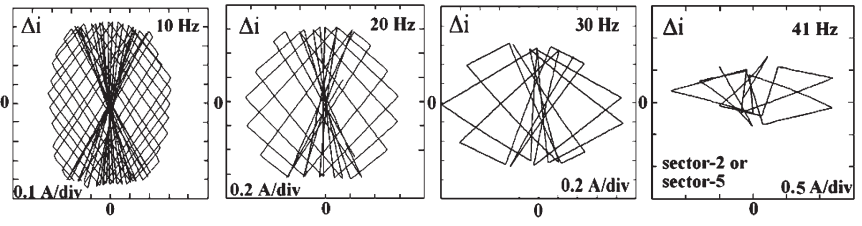

(a)
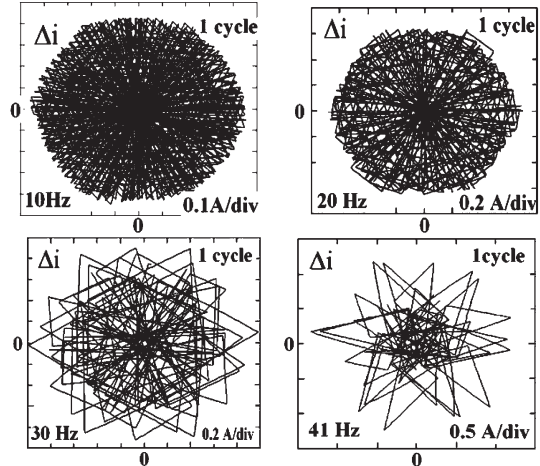

(b)
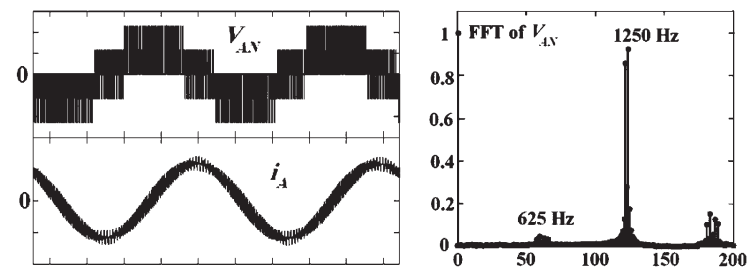

(c)
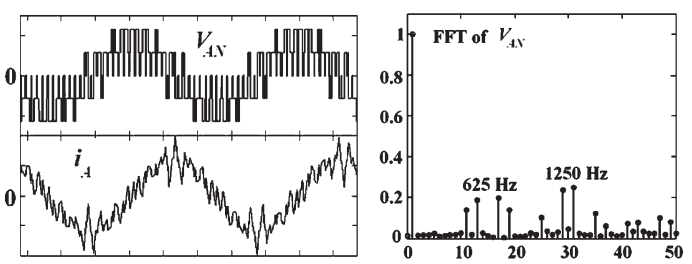

(d)

Fig. 4. (a) Trajectories of $\boldsymbol{\Delta} \mathbf{i}$ on the $\alpha-\beta$ plane in a sector (Sector-2 or Sector-5) for SVPWM-based two-level VSI-fed IM drive for different operating speeds (simulation results). (b) Trajectories of $\Delta \mathbf{i}$ on the $\alpha-\beta$ plane in a fundamental cycle of operation for SVPWM-based two-level VSI-fed IM drive for different operating speeds (simulation results). (c) Simulation results using SVPWM for $10-\mathrm{Hz}$ operation: machine phase voltage $\left(v_{A N}\right)$ and machine phase current $\left(i_{A}\right)$ [ $Y$-axis; upper trace: 1 div. $=100 \mathrm{~V}$, lower trace: 1 div. $=1 \mathrm{~A}, X$-axis: 1 div. $=0.02 \mathrm{~s}$, normalized harmonic spectrum (FFT) of $v_{A N}[Y$-axis: normalized amplitude 1 div. $=0.2, X$-axis: order of harmonic 1 div. $=50$ ]. (d) Simulation results using SVPWM for $40-\mathrm{Hz}$ operation: machine phase voltage $\left(v_{A N}\right)$ and machine phase current $\left(i_{A}\right)$ $[Y$-axis; upper trace: 1 div. $=200 \mathrm{~V}$, lower trace: 1 div. $=1 \mathrm{~A}, X$-axis: 1 div. $=0.005 \mathrm{~s}]$, and normalized harmonic spectrum $(\mathrm{FFT})$ of $v_{A N}[Y$-axis: normalized amplitude $1 \mathrm{div} .=0.2, X$-axis: order of harmonic $1 \mathrm{div} .=10]$.

formed by a set of four unique parabolas. As an example, for $10-\mathrm{Hz}$ operation [Fig. 3(b)], the boundary of $\Delta \mathbf{i}$ is formed by parabola-1 between points $\mathrm{E}$ and $\mathrm{F}$, parabola- 2 between $\mathrm{F}$ and $\mathrm{G}$, parabola-3 between $\mathrm{G}$ and $\mathrm{H}$, and parabola-4 between $\mathrm{H}$ and $\mathrm{E}$. A general equation for a vertical parabola defined with respect to $X-Y$ axes is

$$
(x-h)^{2}=4 p(y-k)
$$

where $(h, k)$ is the vertex, and $p$ is the distance between vertex 


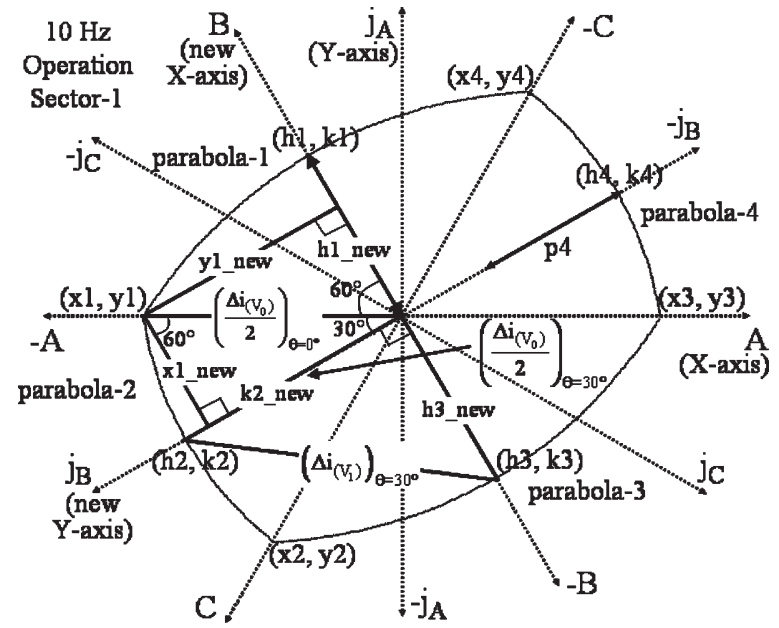

Fig. 5. Finding parameters of boundary defining parabolas with respect to the new reference axis $\left(B\right.$ and $\left.j_{B}\right)$ for Sector-1.

and focus of the parabola. Similarly, a horizontal parabola can be defined as

$$
(y-k)^{2}=4 p(x-h) .
$$

It is to be noted from Figs. 3(b) and 4(a) that for any given sector, the shape and the amplitude of the boundary of $\Delta \mathbf{i}$ vary based on the speed of the machine. Also, the parabolas have different values of vertex and focus for different machines (having different $L_{\sigma}$ ). So, for the proper functioning of the proposed hysteresis controller, it is required, first of all, to properly define the boundaries for $\Delta \mathbf{i}$ for the given operating conditions.

The parabolic boundaries are detected by sensing $\Delta \mathbf{i}$ along $\mathrm{A}, \mathrm{B}$, and $\mathrm{C}$, and $j_{A}, j_{B}$, and $j_{C}$ axes as proposed in [9], [10], and [12]. Fig. 5 shows the boundary for $\Delta \mathbf{i}$ in Sector-1 at $10-\mathrm{Hz}$ operation for the proposed drive on a multiple-axis plane. The complete boundary is divided into four parabolas, as shown in Fig. 5. These four parabolas are intersecting each other at different points. A generalized technique is developed in the proposed work to realize these four parabolas uniquely (to find the focus) from the exact information on $(x 1, y 1)$, $(x 2, y 2),(x 3, y 3),(x 4, y 4)$ and $(h 1, k 1),(h 2, k 2),(h 3, k 3)$, $(h 4, k 4)$. The parameters of the parabolas for different speeds are computed using values of the dc-link voltage $V_{\mathrm{dc}}$ of the inverter, base speed of the machine, stator leakage inductance $L_{\sigma}$ of the machine, and switching interval $T_{S}$. Simple techniques are available in the literature to find $L_{\sigma}$ from terminal measurements [18] for any given induction motor.

The values of the input parameters to generalized technique are $V_{\mathrm{dc}}=350 \mathrm{VDC}$, base frequency $=50 \mathrm{~Hz}, L_{\sigma}=0.0465 \mathrm{H}$ (Appendix), and $T_{S}=800 \mu \mathrm{s}$. For online variation of the boundary of $\Delta \mathbf{i}$ from 1 to $45 \mathrm{~Hz}$ (end of the linear range [17]), a resolution of $1 \mathrm{~Hz}$ is taken in the proposed technique. The amplitude of the machine voltage vector $\left(\mathbf{V}_{\mathbf{m}}\right)$ is found for all the operating frequencies in the linear range using the $V / f$ ratio [17]. Then, the switching times $T_{1}, T_{2}$, and $T_{0}$ are found using (4) for two different angular positions of $\mathbf{V}_{\mathbf{m}}\left(\theta=0^{\circ}\right.$ and $\left.\theta=30^{\circ}\right)$ in a sector. Now, the amplitudes of $\Delta \mathbf{V}_{\left(\mathbf{V}_{\mathbf{k}}\right)}$ are found using the law of parallelogram for both of these angular positions $\mathbf{V}_{\mathbf{m}}$, i.e.,

$$
\begin{aligned}
& \boldsymbol{\Delta} \mathbf{V}_{\left(\mathbf{V}_{\mathbf{1}}\right)}=\sqrt{\left(\mathbf{V}_{\mathbf{m}}\right)^{2}+\left(V_{\mathrm{dc}}\right)^{2}-2\left(\mathbf{V}_{\mathbf{m}}\right)\left(V_{\mathrm{dc}}\right) \cos \theta} \\
& \boldsymbol{\Delta} \mathbf{V}_{\left(\mathbf{V}_{\mathbf{2}}\right)}=\sqrt{\left(\mathbf{V}_{\mathbf{m}}\right)^{2}+\left(V_{\mathrm{dc}}\right)^{2}-2\left(\mathbf{V}_{\mathbf{m}}\right)\left(V_{\mathrm{dc}}\right)\left(\cos \left(60^{\circ}-\theta\right)\right)} \\
& \boldsymbol{\Delta} \mathbf{V}_{\left(\mathbf{V}_{\mathbf{o}}\right)}=\left(\mathbf{V}_{\mathbf{m}}\right) .
\end{aligned}
$$

Then, the amplitudes of $\boldsymbol{\Delta} \mathbf{i}$ during switching of $\mathbf{V}_{\mathbf{1}}, \mathbf{V}_{\mathbf{2}}$, and $\mathbf{V}_{\mathbf{0}}$ are calculated using (6) for $\theta=0^{\circ}$ and $\theta=30^{\circ}$ for operating frequencies from 1 to $45 \mathrm{~Hz}$.

In Fig. 5, parabola-1 and parabola-3 are symmetric around the $B$-axis, and parabola- 2 and parabola- 4 are symmetric around the $j_{B}$-axis. Therefore, $B$-axis is considered as $X$-axis, and $j_{B}$-axis is considered as $Y$-axis [for the parabola definition based on (7) and (8)] for $\Delta \mathbf{i}$ in Sector-1. In Fig. 5, the distance from the center of the plane to point $(x 1, y 1)$ is the amplitude of $\Delta \mathbf{i}$ (i.e., $\left.\Delta \mathrm{i}_{\left(V_{0}\right)} / 2\right)$ when $\mathbf{V}_{\mathbf{m}}$ is just at the start of Sector-1 $\left(\theta=0^{\circ}\right)$ and $\mathbf{V}_{\mathbf{0}}\left(\mathbf{V}_{\mathbf{7}}\right.$ or $\left.\mathbf{V}_{\mathbf{8}}\right)$ is switched for the period $T_{0} / 2$ of the switching interval $T_{S}$. Therefore, the point $\left(x 1 \_n e w\right.$, $y 1 \_$new) with respect to the new reference axis $\left(B\right.$ and $\left.j_{B}\right)$ is calculated using

$$
\begin{aligned}
x 1 \_ \text {new } & =\left(\boldsymbol{\Delta} \mathbf{i}_{\left(\mathbf{V}_{\mathbf{0}}\right)} / 2\right)_{\theta=0^{\circ}} \sin 30^{\circ} \\
& =\left[\left(\left(\boldsymbol{\Delta} \mathbf{V}_{\left(\mathbf{V}_{\mathbf{0}}\right)} / L_{\sigma}\right) T_{0}\right) / 2\right]_{\theta=0^{\circ}} \sin 30^{\circ} \\
y 1 \_ \text {new } & =\left(\boldsymbol{\Delta} \mathbf{i}_{\left(\mathbf{V}_{\mathbf{0}}\right)} / 2\right)_{\theta=0^{\circ}} \cos 30^{\circ} \\
& =\left[\left(\left(\boldsymbol{\Delta} \mathbf{V}_{\left(\mathbf{V}_{\mathbf{0}}\right)} / L_{\sigma}\right) T_{0}\right) / 2\right]_{\theta=0^{\circ}} \cos 30^{\circ}
\end{aligned}
$$

as shown in Fig. 5. In Fig. 5, the distance from the center of the plane to point $(x 2, y 2)$ is the amplitude of $\Delta \mathbf{i}$ (i.e., $\left.\Delta \mathrm{i}_{\left(V_{0}\right)} / 2\right)$ when $\mathbf{V}_{\mathbf{m}}$ is just at the end of Sector-1 $\left(\theta=60^{\circ}\right)$ and $\mathbf{V}_{\mathbf{0}}\left(\mathbf{V}_{\mathbf{7}}\right.$ or $\left.\mathbf{V}_{\mathbf{8}}\right)$ is switched for the period $T_{0} / 2$. Hence, from the symmetry in Fig. 5, it can be noted that $x 2 \_$new $=$ $x 3 \_$new $=-\left(x 1 \_\right.$new $)$, and $x 4 \_$new $=x 1 \_$new. In a similar way, the new $y$ coordinates are $y 2 \_$new $=y 1 \_$new, and $y 3 \_$new $=y 4 \_$new $=-\left(y 1 \_\right.$new $)$.

Now, with the $B$ and $j_{B}$ axes as the new $X$ and $Y$ axes, respectively, it is obvious that the vertex of parabola-1 will be ( $h 1$ new, 0$)$. Similarly, the vertex of parabola-2, parabola-3, and parabola-4 will be at $\left(0, k 2 \_n e w\right),\left(h 3 \_n e w, 0\right)$, and $\left(0, k 4 \_\right.$new $)$, respectively. In Fig. 5 , the distance from the center of the plane to point $(h 2, k 2)$ is the amplitude of $\boldsymbol{\Delta} \mathbf{i}$ when $\mathbf{V}_{\mathbf{m}}$ is just at the center of Sector-1 $\left(\theta=30^{\circ}\right)$ and $\mathbf{V}_{\mathbf{0}}\left(\mathbf{V}_{\mathbf{7}}\right.$ or $\left.\mathbf{V}_{\mathbf{8}}\right)$ is switched for the period $T_{0} / 2$. Therefore, the point $k 2$ new is directly calculated using

$$
\begin{aligned}
k 2 \_ \text {new } & =\left(\boldsymbol{\Delta} \mathbf{i}_{\left(\mathbf{V}_{\mathbf{o}}\right)} / 2\right)_{\theta=30^{\circ}} \\
& =\left[\left(\left(\boldsymbol{\Delta} \mathbf{V}_{\left(\mathbf{V}_{\mathbf{o}}\right)} / L_{\sigma}\right) T_{0}\right) / 2\right]_{\theta=30^{\circ}} .
\end{aligned}
$$

From the symmetry, it is considered that $k 4$ new $=$ $-\left(k 2 \_n e w\right)$. Now, based on Fig. 3(a), the distance between 


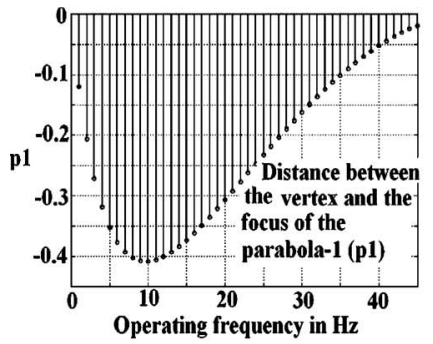

(a)

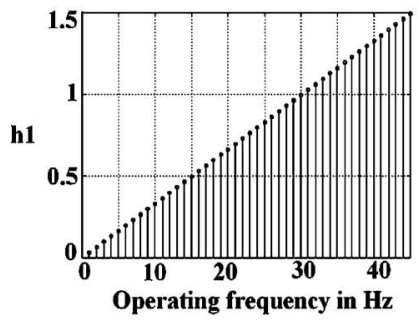

(c)

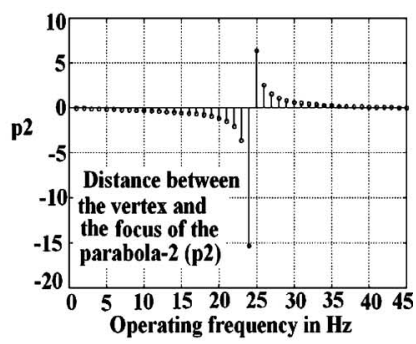

(b)

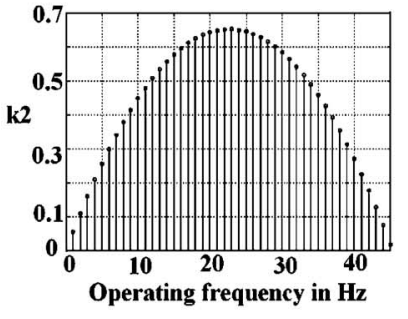

(d)

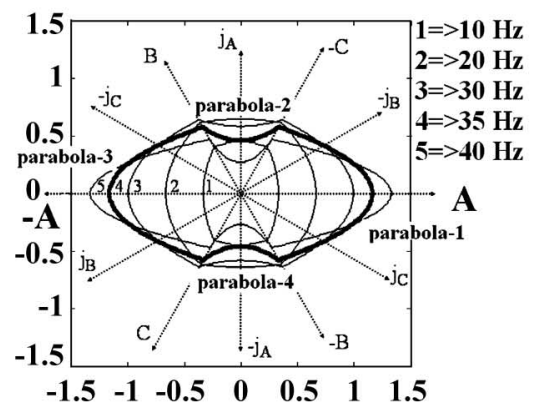

(e)

Fig. 6. Plots of parameters of boundary defining parabolas obtained from the generalized technique to find the boundary for $\Delta \mathbf{i}$. (a) $p 1$, (b) $p 2$, (c) $h 1$, (d) $k 2$, and (e) shape and size of the parabolic boundary of $\boldsymbol{\Delta} \mathbf{i}$ in Sector-2 (or Sector-5) for different operating frequencies [conventional $Y$-axis and $X$-axis: 1 div. $=0.5 \mathrm{~A}]$.

$(h 2, k 2)$ and $(h 3, k 3)$ in Fig. 5 is the amplitude of $\boldsymbol{\Delta} \mathbf{i}$ when $\mathbf{V}_{\mathbf{m}}$ is just at the center of Sector-1 $\left(\theta=30^{\circ}\right)$ and $\mathbf{V}_{\mathbf{1}}$ is switched for the period $T_{1}$ of a sampling interval $T_{S}$. Hence, using geometry, as shown in Fig. 5 , the coordinate $h 3$ new is calculated in the proposed technique as

$$
h 3 \_ \text {new }=\sqrt{\left(\left(\boldsymbol{\Delta} \mathbf{i}_{\left(\mathbf{V}_{\mathbf{1}}\right)}\right)_{\theta=30^{\circ}}\right)^{2}-\left(\left[\boldsymbol{\Delta} \mathbf{i}_{\left(\mathbf{V}_{\mathbf{0}}\right)} / 2\right]_{\theta=30^{\circ}}\right)^{2}} .
$$

For a given operating speed, with $\theta=30^{\circ}$, from (4), it can be shown that $T_{1}=T_{2}$, and hence using (6), it is found that $\left(\boldsymbol{\Delta} \mathbf{i}_{\left(\mathbf{V}_{\mathbf{1}}\right)}\right)_{\theta=30^{\circ}}=\left(\boldsymbol{\Delta} \mathbf{i}_{\left(\mathbf{V}_{\mathbf{2}}\right)}\right)_{\theta=30^{\circ}}$. Therefore, it is considered that $h 1 \_$new $=-\left(h 3 \_\right.$new $)$.

To define the boundary of $\Delta \mathbf{i}$ for any operating speed, it is required to know the focus of all the four parabolas (Fig. 5). In this paper, the values of $p$ (distance between vertex and focus) for parabola-1 to parabola-4 can be determined using (7) and (8) from the available information on the values of $x, y, h$, and $k$ [(10)-(13)] based on the new $X$ - and $Y$-axes ( $B$ and $j B$, respectively, Fig. 5).

Graphical plots of parameters of the boundary defining parabolas are shown in Fig. 6(a)-(d) for parabola-1 and
TABLE I

EQUIVALENT $X$-AXIS AND $Y$-AXIS FOR BOUNDARY DEFINING PARABOLAS IN DIFFERENT SECTORS

\begin{tabular}{|c|c|c|}
\hline Sectors & $\mathrm{X}$-axis & $\mathrm{Y}$-axis \\
\hline 1,4 & B-axis & $\mathrm{j}_{\mathrm{B}}$-axis \\
\hline 2,5 & A-axis & $\mathrm{j}_{\mathrm{A}}$-axis \\
\hline 3,6 & C-axis & $\mathrm{j}_{\mathrm{C}}$-axis \\
\hline
\end{tabular}

parabola-2. In Fig. 6(a), the value of $p 1$ for parabola- 1 is always negative, because parabola- 1 is always toward the center of the plane for different operating frequencies [Fig. 3(b)]. Fig. 6(b) shows the change in polarity of $p 2$ for parabola- 2 at the $25-\mathrm{Hz}$ operation. This is also seen in Fig. 3(b), where parabola-2 is toward the center of the plane for $10-$ and $20-\mathrm{Hz}$ operations, whereas it is outward the plane for $30-$ and $40-\mathrm{Hz}$ operations. The coordinate $h 1$ of the vertex of parabola- 1 has the linear change with respect to the operating frequency, as shown in Fig. 6(c). The variation in $k 2$ of parabola- 2 with operating frequency is shown in Fig. 6(d). The parameters of the parabolas derived based on Sector-1 (Fig. 5) are also applicable for parabolas for other sectors with a change in the reference axes (Table I). The outputs of the generalized technique are used to form the lookup tables for DSP (for practical implementation of the proposed scheme) for online variation of the boundary of $\Delta \mathbf{i}$ (in $1-\mathrm{Hz}$ step) from 1 - to $45-\mathrm{Hz}$ operation of any given machine. For overmodulation mode of operation (above $45 \mathrm{~Hz}$ ), the boundary of $\Delta \mathbf{i}$ is maintained the same as that used for $45-\mathrm{Hz}$ operation, as the switching frequency of the inverter is not a significant concern in the overmodulation mode of operation (leading to the six-step mode) [9]. Fig. 6(e) shows the plot of parabolic boundaries generated for Sector-2 (and Sector-5) using the output of the developed generalized technique.

\section{Adjacent InVerter Voltage Vector Selection and Sector Change Detection in Proposed HySTERESIS CONTROLLER}

In the proposed hysteresis controller, the amplitude of $\Delta \mathbf{i}$ is monitored along the set of $A, B$, and $C$, and $j_{A}, j_{B}$, and $j_{C}$ axes [9], [10], [12]. The controller considers different sets of reference $X$ and $Y$ axes for the boundary defining parabolas, as shown in Table I, for different sectors. Different conditions are set for selecting the proper adjacent inverter voltage vector to keep $\Delta \mathbf{i}$ within the specified parabolic boundary (for a particular speed), as shown in Table II for Sector-1 [9], [10]. For example, for any given speed and for position of $\mathbf{V}_{\mathbf{m}}$ in Sector-1, if $\Delta \mathbf{i}$ is within the axis $-C$ and $-A$ of Fig. 5 (checked by the condition $i_{j C}<0$ and $i_{j A} \geq 0$ in column II of Table II), and simultaneously if $\Delta \mathbf{i}$ goes outside parabola-1 [checked by the condition $\left(y^{2}-4(p 1(x-h 1))\right) \geq 0$ in column II of Table II, based on (8)], then the controller will switch the voltage vector $\mathbf{V}_{\mathbf{1}}$, which will again bring back $\Delta \mathbf{i}$ within the parabolic boundary. In this check, the values of $y$ and $x$ are the online sensed values of the component of $\Delta \mathbf{i}$ on axes $j_{B}$ and $B$, respectively (Table I for Sector-1), while $p 1$ and $h 1$ are the values of the focus and vertex of the particular boundary parabola provided by the proposed generalized technique [Fig. 6(a) and (c)] for that speed. It can be seen from 
TABLE II

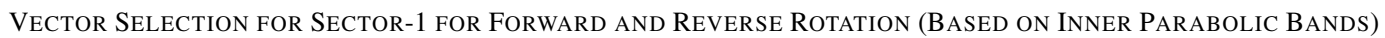

\begin{tabular}{|c|c|c|c|c|c|c|}
\hline \multirow{3}{*}{$\begin{array}{l}\text { Present } \\
\text { vector } \\
\text { "ON" }\end{array}$} & \multicolumn{6}{|c|}{ Conditions to be satisfied and next vector to be switched "ON" } \\
\hline & \multicolumn{2}{|c|}{$\left(\mathrm{y}^{2}-4(\mathrm{p} 1(\mathrm{x}-\mathrm{h} 1))\right) \geq 0$} & \multirow{2}{*}{$\begin{array}{r}\text { up to } 24 \mathrm{~Hz} \text { operation (Fig. 5b) } \\
\left(\mathrm{x}^{2}-4(\mathrm{p} 2(\mathrm{y}-\mathrm{k} 2))\right) \geq 0 \\
25 \mathrm{~Hz} \text { onwards operation (Fig. 5b) } \\
\left(\mathrm{x}^{2}-4(\mathrm{p} 2(\mathrm{y}-\mathrm{k} 2))\right) \leq 0 \\
\mathrm{i}_{\mathrm{j} C}<0 \& \mathrm{ij} \mathrm{i}<0\end{array}$} & \multicolumn{2}{|c|}{$\left(\mathrm{y}^{2}-4(\mathrm{p} 3(\mathrm{x}-\mathrm{h} 3))\right) \geq 0$} & \multirow{2}{*}{$\begin{array}{c}\text { up to } 24 \mathrm{~Hz} \text { operation } \\
\left(\mathrm{x}^{2}-4(\mathrm{p} 4(\mathrm{y}-\mathrm{k} 4))\right) \geq 0 \\
25 \mathrm{~Hz} \text { onwards operation } \\
\left(\mathrm{x}^{2}-4(\mathrm{p} 4(\mathrm{y}-\mathrm{k} 4))\right) \leq 0 \\
\mathrm{i}_{\mathrm{j}} \mathrm{c} \geq 0 \& \mathrm{i}_{\mathrm{j} \mathrm{A}} \geq 0\end{array}$} \\
\hline & $\mathrm{ij}_{\mathrm{j}}<0 \& \mathrm{ij \textrm {A }} \geq 0$ & $\mathrm{i}_{\mathrm{j} A} \geq 0 \& \mathrm{i}_{\mathrm{j} B} \geq 0$ & & $\mathrm{ij}_{\mathrm{j} C} \geq 0 \& \mathrm{ij \textrm {A }}<0$ & $\mathrm{i}_{\mathrm{j} C} \geq 0 \& \mathrm{i} j \mathrm{~A} \geq 0$ & \\
\hline $\mathbf{V}_{1}$ & - & - & - & $V_{2}$ & - & $\mathbf{V}_{7}$ \\
\hline $\mathbf{V}_{2}$ & $\mathbf{V}_{1}$ & - & - & - & - & $\mathbf{V}_{8}$ \\
\hline$V_{7}$ & - & $V_{1}$ & $V_{1}$ & - & $V_{2}$ & - \\
\hline$V_{8}$ & - & $\mathbf{V}_{1}$ & $V_{2}$ & - & $V_{2}$ & - \\
\hline
\end{tabular}

Table II that for parabola-2 and parabola-4, two different checks are provided, out of which the controller will select the one based on the operating speed of the machine. This is because of the fact that parabola- 2 and parabola- 4 change orientation from $25 \mathrm{~Hz}$ onwards operation [ $p 2$, Fig. 6(b)]. Similar checks are carried out for all the other sectors to keep $\Delta \mathbf{i}$ within the parabolic boundary by optimum switching of adjacent inverter voltage vectors. The vector selection logic shown in Table II is applicable for forward and reverse rotation of the machine.

To facilitate the identification of sector change, an outer parallel hysteresis band is proposed, which is similar to [10] and [12]. Sector detection is done by the logic explained in Table III, which uses the outer parabolic bands for detecting the change in the sector. As an example, for forward rotation of the machine, sector change from Sector-1 to Sector-2 is uniquely detected along the $j_{C}$-axis [10], [12], which is checked by the appropriate conditions mentioned in column III of Table III. The sector change logic is self-adaptive and can lead the inverter up to six-step mode of operation if needed. The sector change logic shown in Table III is for the forward rotation of the machine (anticlockwise movement of $\mathbf{V}_{\mathbf{m}}$ ). A similar logic can also be developed for the reverse rotation of the machine.

\section{Simulation Results of Proposed HYSTERESIS CONTROLLER}

Detailed simulation studies of the proposed hysteresis controller scheme are first carried out using Simulink. The parameters of IM used in the proposed simulation studies are given in Appendix. The results of the simulation studies are shown in Fig. 7(a)-(c) for different operating speeds, which is up to the six-step mode of operation. Comparing Fig. 7(a) with Fig. 4(a) and (b) shows that the proposed hysteresis controller keeps $\Delta \mathbf{i}$ within the predefined parabolic boundaries similar to the SVPWM-based inverter. Fig. 7(b) and (c) shows the machine phase voltage $\left(v_{A N}\right)$, phase current $\left(i_{A}\right)$, and normalized harmonic spectrum of $v_{A N}$ at $10-$ and $40-\mathrm{Hz}$ operation, respectively. The voltage and current waveforms in Fig. 7(b) and (c) are similar to the waveforms shown in Fig. 4(c) and (d), respectively, of the SVPWM scheme. The spectrum in Fig. 7(b) and (c) shows a very close resemblance with the spectrums in Fig. 4(c) and (d) (for same frequency of operation of SVPWM scheme). In the proposed scheme, during sector change detection, $\Delta \mathbf{i}$ is allowed to come out of the parabolic boundary (six times in a cycle of operation), and this can cause slight spreading of the sidebands at higher speeds of operation due
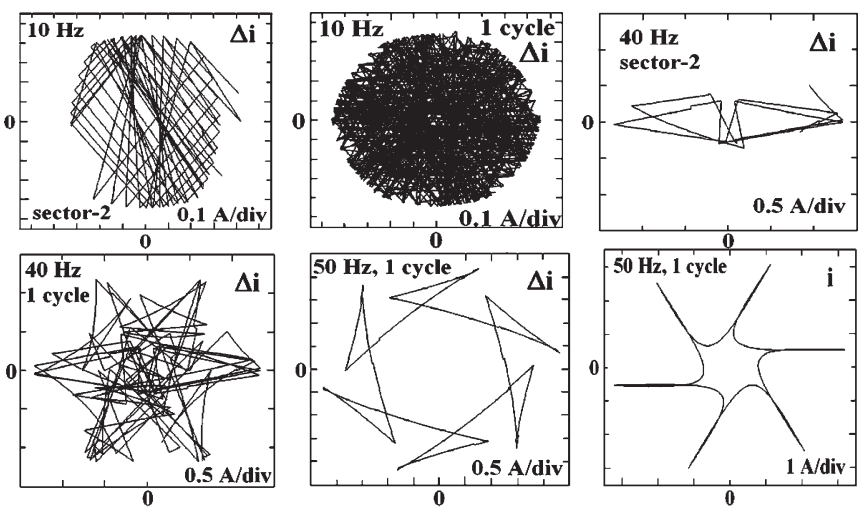

(a)
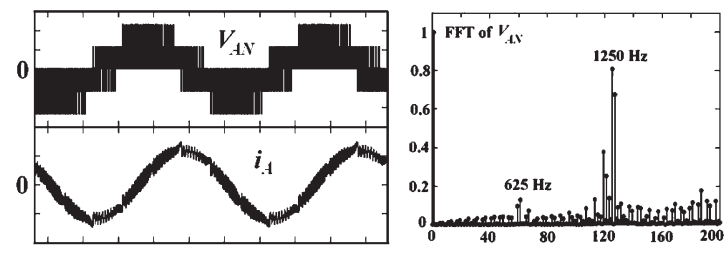

(b)
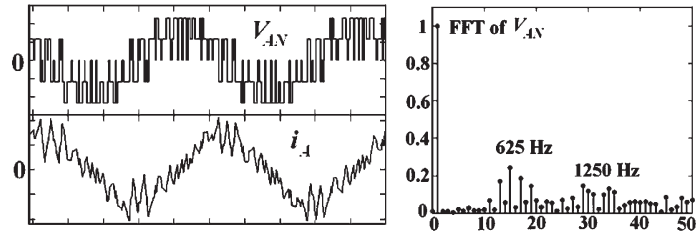

(c)

Fig. 7. (a) Simulation results of the proposed hysteresis controller. Current error space phasor $(\boldsymbol{\Delta} \mathbf{i})$ in a sector and for one cycle of operation, and machine current space phasor (i) on the $\alpha-\beta$ plane. (b) Simulation results for the proposed hysteresis controller for $10-\mathrm{Hz}$ operation: machine phase voltage $\left(v_{A N}\right)$ and machine phase current $\left(i_{A}\right)[Y$-axis; upper trace: 1 div. $=100 \mathrm{~V}$, lower trace: $1 \mathrm{div} .=1 \mathrm{~A}, X$-axis: $1 \mathrm{div} .=0.02 \mathrm{~s}$ ], and normalized harmonic spectrum (FFT) of $v_{A N}[Y$-axis: normalized amplitude 1 div. $=0.2, X$-axis: order of harmonic 1 div. $=20$ ]. (c) Simulation results for the proposed hysteresis controller for $40-\mathrm{Hz}$ operation: machine phase voltage $\left(v_{A N}\right)$ and machine phase current $\left(i_{A}\right)[Y$-axis; upper trace: 1 div. $=100 \mathrm{~V}$, lower trace: $1 \mathrm{div} .=1 \mathrm{~A}, X$-axis: 1 div. $=0.005 \mathrm{~s}$, and normalized harmonic spectrum (FFT) of $v_{A N}$ [ $Y$-axis: normalized amplitude 1 div. $=0.2, X$-axis: order of harmonic 1 div. $=10]$.

to the 5th and 7th harmonics of the fundamental [Fig. 7(b) and (c)]. However, the boundary $\Delta \mathbf{i}$ of the proposed hysteresis controller [Fig. 7(a)] is shape wise and size wise quite similar to the boundary shown in Fig. 4(a) and (b) with SVPWM control. This proves the concept of switching frequency variation control in the proposed hysteresis controller. 
TABLE III

Sector Change Logic (BAsed on Outer Parabolic Bands) For Forward Rotation of Machine

\begin{tabular}{|c|c|c|c|c|c|c|c|}
\hline \multirow{3}{*}{$\begin{array}{l}\text { From } \\
\text { sector }\end{array}$} & \multirow{3}{*}{$\begin{array}{c}\text { Present } \\
\text { Vector "ON" }\end{array}$} & \multicolumn{6}{|c|}{ Condition to be satisfied for the sector change and next sector to be considered as new sector } \\
\hline & & \multicolumn{3}{|c|}{$\left(\mathrm{y}^{2}-4(\mathrm{p} 3\right.$ outer $(\mathrm{x}-\mathrm{h} 3$ outer $\left.))\right) \geq 0$} & \multicolumn{3}{|c|}{$\left(\mathrm{y}^{2}-4(\mathrm{p} 1\right.$ outer(y-h1_outer $\left.\left.)\right)\right) \geq 0$} \\
\hline & & $\mathrm{i}_{\mathrm{jA}}<0 \& \mathrm{i}_{\mathrm{jB}}<0$ & $\mathrm{i}_{\mathrm{jB}}<0 \& \mathrm{i}_{\mathrm{j}} \mathrm{C}<0$ & $\mathrm{i}_{\mathrm{jC}}<0 \& \mathrm{i}_{\mathrm{j} A}<0$ & $\mathrm{ij} \mathrm{C} \geq 0 \& \mathrm{ijA} \geq 0$ & $\mathrm{i} j \mathrm{j}_{\mathrm{A}} \geq 0 \& \mathrm{ijB} \geq 0$ & $\mathrm{ijB} \geq 0 \&$ i $\mathrm{ijC} \geq 0$ \\
\hline 1 & $\mathbf{V}_{2}$ or $\mathbf{V}_{7}$ or $\mathbf{V}_{8}$ & 2 & $*$ & * & * & * & * \\
\hline 2 & $\mathbf{V}_{3}$ or $\mathbf{V}_{7}$ or $\mathbf{V}_{8}$ & $*$ & * & $*$ & 3 & * & * \\
\hline 3 & $\mathbf{V}_{4}$ or $\mathbf{V}_{7}$ or $\mathbf{V}_{8}$ & $*$ & 4 & * & * & * & $*$ \\
\hline 4 & $\mathbf{V}_{5}$ or $\mathbf{V}_{7}$ or $\mathbf{V}_{8}$ & * & * & $*$ & * & 5 & * \\
\hline 5 & $\mathbf{V}_{6}$ or $\mathbf{V}_{7}$ or $\mathbf{V}_{8}$ & $*$ & $*$ & 6 & * & $*$ & $*$ \\
\hline 6 & $V_{1}$ or $V_{7}$ or $V_{8}$ & * & * & * & * & * & 1 \\
\hline
\end{tabular}

\section{EXPERIMENTAL RESULTS}

The proposed hysteresis controller is implemented on a 3.7-kW IM (Appendix) drive fed with a two-level VSI using vector control [12]. The machine currents are sensed on two phases only. The proposed hysteresis controller is completely implemented on a TMS320LF2407A DSP controller platform. The boundary of $\Delta \mathbf{i}$ is implemented using the parameters of boundary defining parabolas provided by the generalized technique described in Section IV [Fig. 6(a)-(d)]. Vector selection and sector detection are achieved using lookup tables (Tables II and III) inside the DSP.

Figs. 8-11 show the experimental results of the proposed hysteresis-controller-fed IM drive in steady-state operations up to the six-step mode. Because of the sector change detection using outer parabola boundaries, multiples of the 5th and 7 th harmonics are also present with small amplitudes in the spectrums shown in Figs. 8-10. These harmonics can be further reduced by selecting the outer band (for sector change detection) very close to the main band and by using faster DSPs. To prove the performance of the proposed scheme, experimental waveforms of the components of $\Delta \mathbf{i}$ along the $\alpha$-axis and $\beta$-axis are captured using storage scope and shown in Figs. 8-11 for various steady-state speeds of operation. It can be seen from these plots that the proposed hysteresis controller keeps $\Delta \mathbf{i}$ within the predefined parabolic boundaries. All the steady-state experimental plots of the boundary of $\Delta \mathbf{i}$ are in agreement with the simulation results.

Experimental results demonstrating transient performance of the proposed controller are shown in Fig. 12. Fig. 12(a) shows smooth transition to the six-step mode [9], [10]. Fig. 12(b) shows transient performance of the proposed controller during speed reversal, where the actual current follows the reference current. This current control is achieved by online variation of the parabolic boundary with different speeds and with resolution of $1 \mathrm{~Hz}$. All the experimental results demonstrate smooth steady-state and dynamic performance, and excellent tracking of machine phase current with the reference phase current throughout the transitions with switching frequency variation control. The present parabolic boundary approach can also be used for front-end active rectifiers with constant fundamental frequency for input current shaping [20]. The present scheme for two-level inverters can also be extended to PWM control of multilevel inverters, where the conventional SVPWM technique [21] is complex to implement, with switching time computations in various sectors, as the number of levels increases.

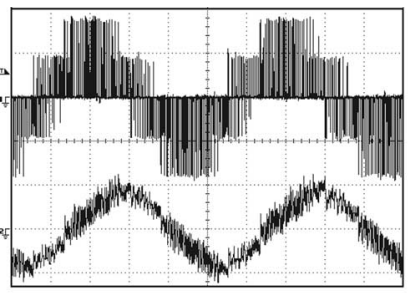

(a)

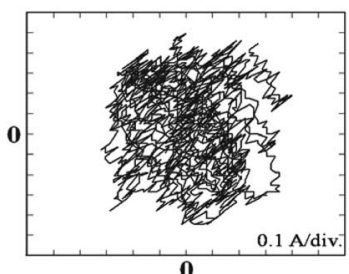

(c)

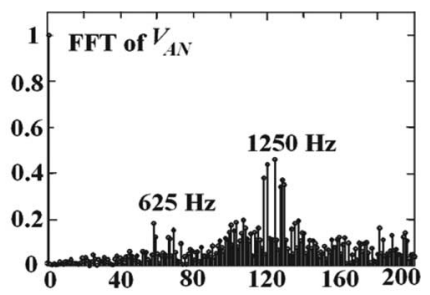

(b)

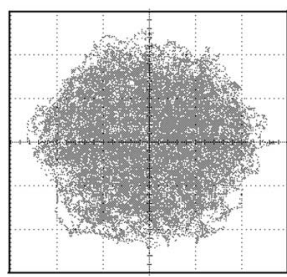

(d)
Fig. 8. Ten-hertz operation. (a) Machine phase voltage $\left(v_{A N}\right)$ and machine phase current $\left(i_{A}\right)$ [ $Y$-axis; upper trace: 1 div. $=130 \mathrm{~V}$, lower trace: 1 div. $=$ $1.3 \mathrm{~A}, X$-axis: 1 div. $=20 \mathrm{~ms}$. (b) FFT of $v_{A N}$ [Y-axis: normalized amplitude 1 div. $=0.2, X$-axis: order of harmonic 1 div. $=20]$. (c) $\Delta \mathbf{i}$ in Sector-2, (d) $\Delta \mathbf{i}$ for all the six sectors $[Y$-axis and $X$-axis: 1 div. $=0.2 \mathrm{~A}]$.

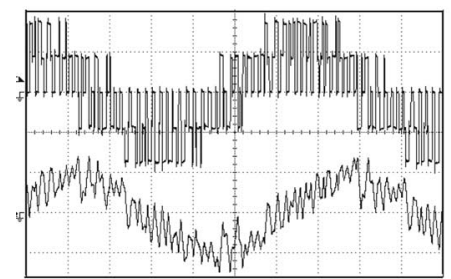

(a)

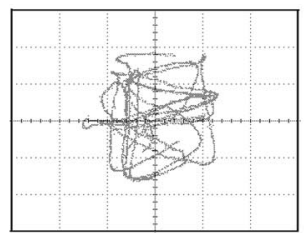

(c)

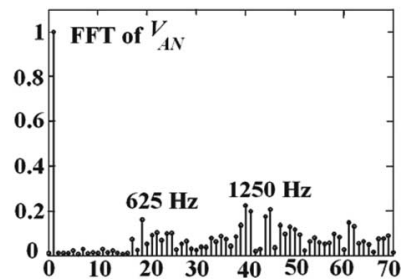

(b)

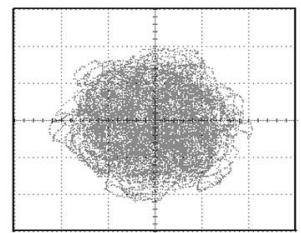

(d)
Fig. 9. Thirty-hertz operation. (a) Machine phase voltage $\left(v_{A N}\right)$ and machine phase current $\left(i_{A}\right)$ [ $Y$-axis; upper trace: 1 div. $=135 \mathrm{~V}$, lower trace: 1 div. $=$ $1.3 \mathrm{~A}, X$-axis: 1 div. $=5 \mathrm{~ms}$. (b) FFT of $v_{A N}[Y$-axis: normalized amplitude 1 div. $=0.2, X$-axis: order of harmonic 1 div. $=10]$. (c) and (d) $\Delta \mathbf{i}$ in Sector-3 and for all the six sectors, respectively [ $Y$-axis and $X$-axis: 1 div. $=$ $0.45 \mathrm{~A}]$.

\section{CONCLUSION}

A novel concept of online variation of the parabolic boundary for current error space phasor is proposed to minimize 


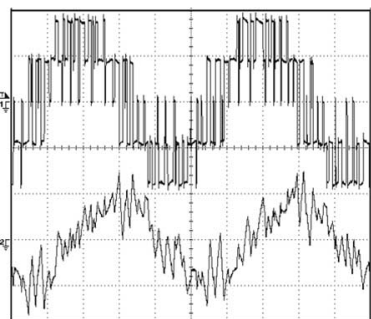

(a)

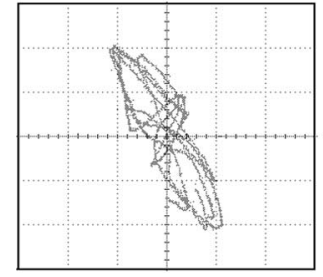

(c)

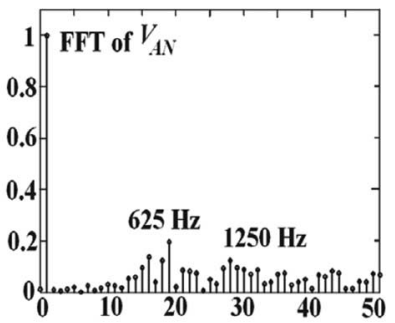

(b)

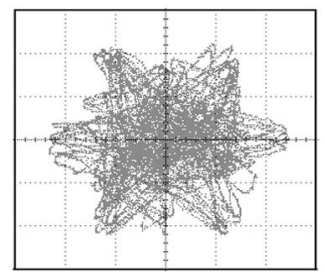

(d)
Fig. 10. Forty-hertz operation. (a) Machine phase voltage $\left(v_{A N}\right)$ and machine phase current $\left(i_{A}\right)[Y$-axis; upper trace: 1 div. $=130 \mathrm{~V}$, lower trace: 1 div. $=1.3 \mathrm{~A}, X$-axis: 1 div. $=5 \mathrm{~ms}]$. (b) FFT of $v_{A N}[Y$-axis: normalized amplitude 1 div. $=0.2, X$-axis: order of harmonic 1 div. $=5]$. (c) and (d) $\Delta \mathbf{i}$ in Sector- 1 and for all the six sectors, respectively $[Y$-axis and $X$-axis: 1 div. $=0.6 \mathrm{~A}]$.

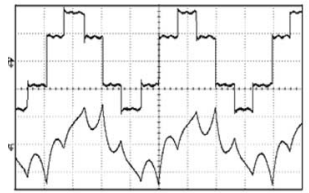

(a)

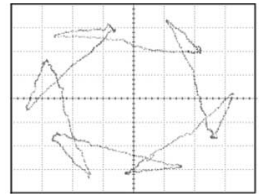

(b)

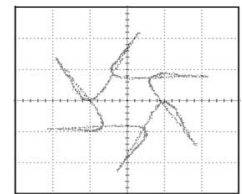

(c)
Fig. 11. Fifty-hertz (six-step) operation. (a) Machine phase voltage $\left(v_{A N}\right)$ and machine phase current $\left(i_{A}\right)$ [ $Y$-axis; upper trace: 1 div. $=130 \mathrm{~V}$, lower trace: 1 div. $=1.3 \mathrm{~A}, X$-axis: $1 \mathrm{div}$. $=5 \mathrm{~ms}]$. (b) $\boldsymbol{\Delta} \mathbf{i}$ for one fundamental cycle [ $Y$-axis and $X$-axis: 1 div. $=0.65 \mathrm{~A}$ ]. (c) Machine current space phasor (i) for one fundamental cycle $[Y$-axis and $X$-axis: 1 div. $=1.4 \mathrm{~A}]$.

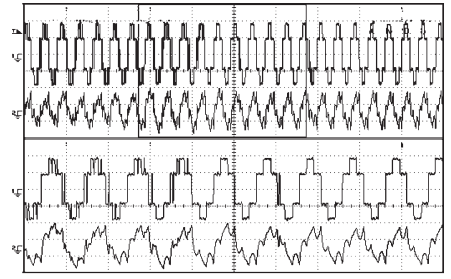

(a)

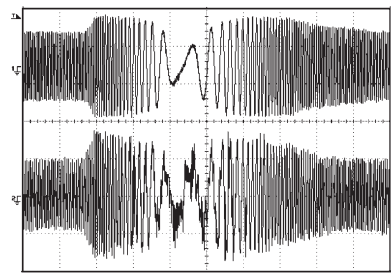

(b)
Fig. 12. Transient performance. (a) Machine phase voltage and machine phase current during transition from $45-$ to $50-\mathrm{Hz}$ operation: top trace [ $Y$-axis; upper trace: 1 div. $=130 \mathrm{~V}$, lower trace: 1 div. $=1.5 \mathrm{~A}, X$-axis: 1 div. $=$ $50 \mathrm{~ms}$, zoomed bottom trace [ $Y$-axis; upper trace: 1 div. $=130 \mathrm{~V}$, lower trace: 1 div. $=1.5 \mathrm{~A}, X$-axis: $1 \mathrm{div} .=20 \mathrm{~ms}$ ]. (b) speed reversal operation; upper trace: reference machine phase current $\left(i_{A}^{*}\right)$, and lower trace: machine phase current $\left(i_{A}\right)$ [ $Y$-axis; upper and lower traces: 1 div. $=1.35 \mathrm{~A}, X$-axis: 1 div. $=500 \mathrm{~ms}$.

switching frequency variation in hysteresis-controller-based two-level VSI-fed IM drives. The proposed hysteresis controller obtains a switching frequency spectrum of the output voltage that is similar to that of the constant switching frequency SVPWM-based IM drive. A generalized technique that determines the set of unique parabolic boundaries for a two-level inverter feeding any given induction motor is developed. Sector change logic is self-adaptive and is capable of taking the drive up to six-step mode if needed. Simple lookup tables are only needed for the proposed controller. Steadystate and transient performance of the proposed controller is experimentally verified on a $3.7-\mathrm{kW}$ IM drive for the entire operating range up to six-step mode. The experimental results are in good agreement with the simulation results. All other inherent advantages of space phasor based hysteresis current controller such as adjacent voltage vector switching, no need of machine back EMF calculation, and fast dynamic response are retained in the proposed scheme in addition to switching frequency variation control and optimum PWM switching.

\section{APPENDIX}

Induction motor parameters: $3.7 \mathrm{~kW}$, three phases, rated voltage: $415 \mathrm{~V}, 50 \mathrm{~Hz}$, rated speed: $1445 \mathrm{r} / \mathrm{min}$, four poles, $R_{s}=4.8 \Omega, R_{r}=3.8 \Omega, L_{s}=0.5632 \mathrm{H}, L_{r}=0.577 \mathrm{H}$, and $M=0.546 \mathrm{H}$.

\section{REFERENCES}

[1] D. M. Brod and D. W. Novotny, "Current control of VSI-PWM inverters," IEEE Trans. Ind. Appl., vol. IA-21, no. 4, pp. 562-570, May/Jun. 1985.

[2] M. P. Kazmierkowski and L. Malesani, "Current control techniques for three-phase voltage-source PWM converters: A survey," IEEE Trans. Ind. Electron., vol. 45, no. 5, pp. 691-703, Oct. 1998.

[3] I. Nagy, Z. Suto, and L. Backhausz, "Periodic states of hysteresis current control of induction motor," in Proc. 29th Eur. Conf. PCIM, Nurnberg, Germany, May 21-23, 1996, pp. 605-619.

[4] A. Nabae, S. Ogasawara, and H. Akagi, "A novel control scheme for current-controlled PWM inverters," IEEE Trans. Ind. Appl., vol. IA-22, no. 4, pp. 697-701, Jul./Aug. 1986.

[5] M. P. Kazmierkowski, M. A. Dzieniakowski, and W. Sulkowski, "Novel space vector based current controllers for PWM-inverters," IEEE Trans. Power Electron., vol. 6, no. 1, pp. 158-166, Jan. 1991.

[6] M. P. Kazmierkowski and W. Sulkowski, "A novel vector control scheme for transistor PWM inverter-fed induction motor drive," IEEE Trans. Ind. Electron., vol. 38, no. 1, pp. 41-47, Feb. 1991.

[7] I. Nagy and L. Backhausz, "Current control of VSI-PWM inverters for vector controlled drives," in Proc. 25th Eur. Conf. PCIM, Nurnberg, Germany, Jun. 28-30, 1994, pp. 397-413.

[8] I. Nagy, "Novel adaptive tolerance band based PWM for field-oriented control of induction machines," IEEE Trans. Ind. Electron., vol. 41, no. 4, pp. 406-417, Aug. 1994.

[9] V. M. Mistry, S. P. Waikar, K. Gopakumar, L. Umanand, and V. T. Ranganathan, "A multi axis space phasor based current hysteresis controller for PWM inverters," EPE J., vol. 10, no. 1, pp. 17-25, Apr. 2000.

[10] M. R. Baiju, K. K. Mohapatra, R. S. Kanchan, P. N. Tekwani, and K. Gopakumar, "A space phasor based current hysteresis controller using adjacent inverter voltage vectors with smooth transition to six step operation for a three phase voltage source inverter," EPE J., vol. 15, no. 1, pp. 36-47, Feb. 2005.

[11] K. A. Corzine, "A hysteresis current-regulated control for multi-level drives," IEEE Trans. Energy Convers., vol. 15, no. 2, pp. 169-175, Jun. 2000.

[12] P. N. Tekwani, R. S. Kanchan, and K. Gopakumar, "Current-error spacevector-based hysteresis PWM controller for three-level voltage source inverter fed drives," Proc. Inst. Electr. Eng.-Electric Power Applications, vol. 152, no. 5, pp. 1283-1295, Sep. 2005.

[13] L. Malesani and P. Tenti, "A novel hysteresis control method for currentcontrolled voltage-source PWM inverters with constant modulation frequency," IEEE Trans. Ind. Appl., vol. 26, no. 1, pp. 88-92, Jan./Feb. 1990.

[14] B. K. Bose, "An adaptive hysteresis-band current control technique for a voltage-fed PWM inverter for machine drive system," IEEE Trans. Ind. Electron., vol. 37, no. 5, pp. 402-408, Oct. 1990. 
[15] Q. Yao and D. G. Holmes, "A simple, novel method for variablehysteresis-band current control of a three phase inverter with constant switching frequency," in Proc. Conf. Rec. IEEE IAS Annu. Meeting, Oct. 2-8, 1993, vol. 2, pp. 1122-1129.

[16] L. Malesani, P. Mattavelli, and P. Tomasin, "Improved constant-frequency hysteresis current control for VSI inverters with simple feedforward bandwidth prediction," IEEE Trans. Ind. Appl., vol. 33, no. 5, pp. 1194-1202, Sep./Oct. 1997.

[17] H. W. Van Der Broeck, H. C. Skudelny, and G. V. Stanke, "Analysis and realization of a pulsewidth modulator based on voltage space vectors," IEEE Trans. Ind. Appl., vol. 24, no. 1, pp. 142-150, Jan./Feb. 1988

[18] A. M. Khambadkone and J. Holtz, "Vector-controlled induction motor drive with a self-commissioning scheme," IEEE Trans. Ind. Electron., vol. 38, no. 5, pp. 322-327, Oct. 1991.

[19] W. Stefanutti and P. Mattavelli, "Fully digital hysteresis modulation with switching-time prediction," IEEE Trans. Ind. Appl., vol. 42, no. 3, pp. 763-769, May/Jun. 2006.

[20] S. Choi, "A three-phase unity-power-factor diode rectifier with active input current shaping," IEEE Trans. Ind. Electron., vol. 52, no. 6, pp. 1711-1714, Dec. 2005.

[21] A. K. Gupta and A. M. Khambadcone, "A space vector PWM scheme for multilevel inverters based on two-level space vector PWM," IEEE Trans. Ind. Electron., vol. 53, no. 5, pp. 1631-1639, Oct. 2006.

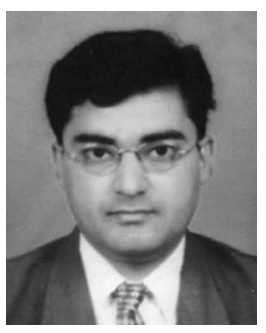

P. N. Tekwani (S'04) received the B.E. degree in power electronics from Saurashtra University, Morbi, India, in 1995, the M.E. degree in electrical engineering from M.S. University, Vadodara, India, in 2000 , and the Ph.D. degree from the Indian Institute of Science, Bangalore, India.

From 1995 to 1996, he was with Amtech Electronics, Gandhinagar, India. From 1996 to 2001, he was with the Electrical Research and Development Association, Vadodara. From 2001 to 2006, he was a Member of the faculty at the Nirma University of Science and Technology, Ahmedabad, India. He is currently with Nirma University of Science and Technology, Ahmedabad, India.

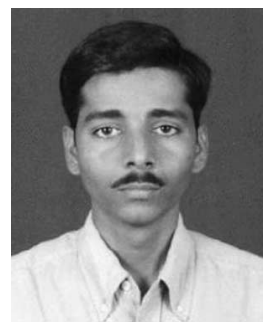

R. S. Kanchan (S'04) received the B.E. degree in electrical engineering from Walchand College of Engineering, Sangali, India, in 1998, the M.Tech. degree in electrical engineering from the Indian Institute of Technology, Bombay, India, in 2000, and the $\mathrm{Ph} . \mathrm{D}$. degree from the Indian Institute of Science, Bangalore, India, in 2005.

From 2000 to 2002, he was with Tata Steel Company, Jamshedpur, India. He is currently a Research Associate at the Centre for Electronics Design and Technology (CEDT), Indian Institute of Science.

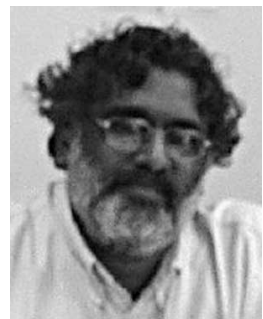

K. Gopakumar (M'94-SM'96) received the B.E., M.Sc. (Eng.), and Ph.D. degrees from the Indian Institute of Science, Bangalore, India, in 1980, 1984, and 1994, respectively.

From 1984 to 1987, he was with the Indian Space Research Organization. He is currently an Associate Professor at the Centre for Electronics Design and Technology (CEDT), Indian Institute of Science. His fields of interest are power converters, PWM techniques, and ac drives.

Dr. Gopakumar is a Fellow of the Institution of Electrical and Telecommunication Engineers (IETE), India. He is currently an Associate Editor for the IEEE TRANSACTIONS ON INDUSTRIAL ELECTRONICS. 